\title{
Lipases bacterianas: impactos na qualidade de produtos lácteos e potencial
}

\section{biotecnológico}

\author{
Bacterial lipases: impacts on dairy product quality and biotechnological potential \\ Lipasas bacterianas: impactos en la calidad de los productos lácteos y el potencial biotecnológico
}

Recebido: 29/09/2021 | Revisado: 04/10/2021 | Aceito: 07/10/2021 | Publicado: 10/10/2021

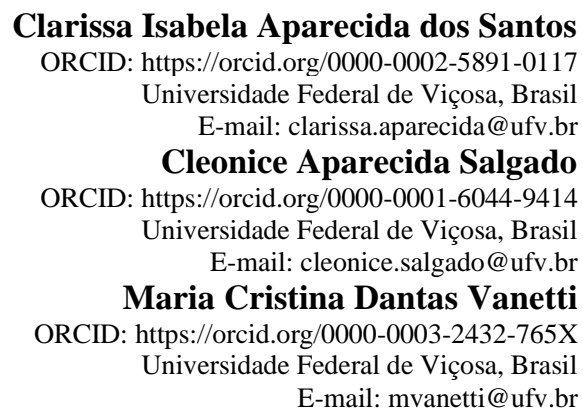

\begin{abstract}
Resumo
Lipases são enzimas que catalisam a hidrólise de triacilgliceróis, com liberação de ácidos graxos que podem estar associadas com a deterioração de muitos alimentos. Por outro lado, as lipases de origem microbiana apresentam características desejáveis para serem utilizadas em diversas aplicações biotecnológicas e são consideradas biocatalisadores versáteis, atuantes numa variedade de reações químicas. O objetivo deste trabalho foi avaliar, por meio de revisão da literatura, o impacto de lipases bacterianas na qualidade de produtos lácteos e o potencial biotecnológico dessas enzimas. Bactérias psicrotróficas isoladas do leite cru refrigerado, comumente secretam lipases termorresistentes, um problema para a indústria laticinista, pois resistem aos tratamentos térmicos utilizados e permanecem no produto lácteo acabado. Os ácidos graxos liberados durante a lipólise contribuem para o sabor forte, rançoso e de sabão dos produtos lácteos, tornando-os inaceitáveis pelo consumidor. No entanto, quando esta atividade é controlada, as lipases atuam no desenvolvimento de atributos sensoriais desejáveis. Por exemplo, em alguns queijos de maturação prolongada a atividade lipolítica é essencial para o desenvolvimento de sabores característicos. Além disso, as lipases apresentam grande potencial de aplicação biotecnológica, inclusive na degradação de poliuretanos, configurando vantagem para a indústria. Portanto, as lipases podem causar defeitos nos produtos lácteos, mas também são de grande interesse industrial quando sua atividade é explorada.
\end{abstract}

Palavras-chave: Enzimas lipolíticas; Psicrotróficas; Lipólise.

\begin{abstract}
Lipases are enzymes that catalyze the hydrolysis of triacylglycerols, releasing fatty acids that can be associated with the spoilage of many foods. On the other hand, lipases of microbial origin present desirable characteristics to be used in several biotechnological applications and are considered versatile biocatalysts, acting in a variety of chemical reactions. The objective of this work was to evaluate, through a literature review, the impact of bacterial lipases on the quality of dairy products and the biotechnological potential of these enzymes. Psychrotrophic bacteria isolated from refrigerated raw milk commonly secrete heat resistant lipases, a problem for the dairy industry, as they resist heat treatments used and remain in the finished dairy product. Fatty acids released during lipolysis contribute to the strong, rancid, soapy taste of dairy products, making them unacceptable to the consumer. However, when this activity is controlled, lipases act in the development of desirable sensory attributes. For example, in some cheeses that mature for a long time, lipolytic activity is essential for the development of characteristic flavors. In addition, lipases have great potential for biotechnological application, including in the degradation of polyurethanes, representing an advantage for the industry. Therefore, lipases can cause defects in dairy products, but they are also of great industrial interest when their activity is explored.
\end{abstract}

Keywords: Lipolytic enzymes; Psychrotrophic; Lipolysis.

\section{Resumen}

Las lipasas son enzimas que catalizan la hidrólisis de los triacilgliceroles, liberando ácidos grasos que pueden estar asociados con el deterioro de muchos alimentos. Por otro lado, las lipasas de origen microbiano presentan 
características deseables para ser utilizadas en varias aplicaciones biotecnológicas y se consideran biocatalizadores versátiles, actuando en una variedad de reacciones químicas. El objetivo de este trabajo fue evaluar, mediante una revisión de la literatura, el impacto de las lipasas bacterianas en la calidad de los productos lácteos y el potencial biotecnológico de estas enzimas. Las bacterias psicrotróficas aisladas de la leche cruda refrigerada comúnmente secretan lipasas resistentes al calor, un problema para la industria láctea, ya que resisten los tratamientos térmicos utilizados y permanecen en el producto lácteo terminado. Los ácidos grasos liberados durante la lipólisis contribuyen al sabor fuerte, rancio y jabonoso de los productos lácteos, lo que los hace inaceptables para el consumidor. Sin embargo, cuando se controla esta actividad, las lipasas actúan en el desarrollo de atributos sensoriales deseables. Por ejemplo, en algunos quesos que maduran mucho tiempo, la actividad lipolítica es fundamental para el desarrollo de sabores característicos. Además, las lipasas tienen un gran potencial para aplicaciones biotecnológicas, incluida la degradación de poliuretanos, lo que representa una ventaja para la industria. Por tanto, las lipasas pueden provocar defectos en los productos lácteos, pero también son de gran interés industrial cuando se explora su actividad.

Palabras clave: Enzimas lipolíticas; Psicrotróficas; Lipólisis.

\section{Introdução}

As lipases são enzimas hidrolíticas pertencentes ao grupo das serina hidrolases que catalisam a hidrólise de ligações éster-carboxílicas. Hidrolisam preferencialmente substratos com ácidos graxos de cadeia longa com mais de 10 carbonos, mas também podem hidrolisar substratos com ácidos graxos de cadeia curta e intermediária (Anthonsen et al., 1995; Chen et al., 2003; Jaeger et al., 1999). No leite e derivados estas enzimas atuam na hidrólise dos triacilgliceróis presentes na gordura, podendo causar defeitos de sabor e aroma nos produtos lácteos (Deeth, 2006; Wiking, 2020).

As enzimas extracelulares podem resistir à pasteurização do leite a $72{ }^{\circ} \mathrm{C}$ por $15 \mathrm{~s}$ e ao tratamento de ultra-alta temperatura (UHT), conduzido geralmente a $140{ }^{\circ} \mathrm{C}$ durante 2 a 10 s (Hantsis-Zacharov e Halpern, 2007). Portanto, a termoestabilidade das lipases produzidas por microrganismos psicrotróficos torna-se um problema para a indústria laticinista, uma vez que resistem aos tratamentos térmicos utilizados e permanecem no produto acabado (Marchand et al., 2009). Entretanto, nos processos industriais onde a atividade de lipases é necessária, a estabilidade térmica é uma característica desejável uma vez que altas temperaturas são empregadas nas reações lipolíticas, principalmente devido ao alto ponto de fusão dos substratos lipídicos que participam do processo (Sangeetha; Arulpandi; Geetha, 2011).

A introdução do armazenamento refrigerado do leite em fazendas acentuou o efeito da lipólise causada por lipases de origem bacteriana, uma vez que com a refrigeração favorece o aumento da população bacteriana psicrotrófica, capaz de produzir lipases extracelulares (Deeth, 2011). Entre as bactérias psicrotróficas que produzem enzimas lipolíticas, Pseudomonas é o gênero predominante entre os Gram-negativos e Bacillus, o predominante entre os Gram-positivos (Vithanage et al., 2016; Yuan et al., 2017; Zhang et al., 2019). No entanto, outros gêneros bacterianos isolados a partir de leite cru também podem produzir enzimas lipolíticas, como Serratia, Hafnia, Acinetobacter, Microbacterium, Enterobacter, Flavobacterium e Sphingobacterium (Hantsis-Zacharov; Halpern, 2007; Decimo et al., 2014; Vithanage et al., 2016; Yuan et al., 2017; Salgado et al., 2020).

Bactérias psicrotróficas como: Acinetobacter harbinensis, Flavobacterium plurextorum, Flavimonas oryzihabitan, Pseudomonas hunanensis, Pseudomonas yamanorum, Rahnella inusitata, Rheinheimera chironomi e Sphingobacterium anhuiense, embora presentes em baixa quantidade no leite cru, também podem causar sua deterioração, mesmo que tal potencial ainda precise ser mais investigado (Yuan et al., 2017). Ribeiro Júnior e colaboradores (2018) verificaram que, entre as bactérias psicrotróficas isoladas do leite cru refrigerado brasileiro, as espécies lipolíticas de maior destaque foram Enterobacter kobei, Lactococcus lactis, Aerococcus urinaeequi e Acinetobacter lwoffii. Salgado e colaboradores (2020) verificaram que os 17 isolados de Serratia liquefaciens obtidos de leite cru brasileiro eram lipolíticos, sendo que 47,05\% deles apresentaram alta atividade lipolítica. 
As lipases são consideradas enzimas versáteis e tem ampla aplicação biotecnológica, sendo que, as de origem bacteriana são as de maior interesse, devido à recuperação fácil e barata, além de outras vantagens. Lipases derivadas de bactérias psicrotróficas comumente encontradas no leite cru refrigerado têm sido exploradas pelo potencial biotecnológico que apresentam, como a capacidade de degradar poliuretano, polímero plástico altamente poluente (Salgado et al., 2021). Considerando a importância das lipases, o objetivo deste trabalho foi avaliar, por meio de revisão da literatura, o impacto de lipases bacterianas na qualidade de produtos lácteos e o potencial biotecnológico dessas enzimas.

\section{Metodologia}

Este artigo é uma revisão bibliográfica dos impactos das lipases de bactérias psicrotróficas na qualidade sensorial do leite e seus derivados, e também da exploração do potencial biotecnológico destas enzimas. O trabalho é baseado numa pesquisa qualitativa em bases de dados online (ScienceDirect, Scielo, PubMed, Periódicos CAPES), que forneceram artigos científicos originais indexados. O levantamento bibliográfico foi realizado utilizando as palavras-chave: Lipase, psicrotróficos, leite, deterioração, aplicação e biotecnológica. Os artigos mais relevantes e mais recentes, escritos em português, inglês ou espanhol foram incluídos para compor a introdução e a discussão deste trabalho (Pereira et al., 2018).

\section{Resultados e Discussão}

\section{Enzimas lipolíticas}

Enzimas lipolíticas, também chamadas de carboxilesterases, são divididas em dois grupos, as lipases ou triacilglicerol acil hidrolases (EC 3.1.1.3) e as esterases ou carboxilases (EC 3.1.1.1). As lipases e as esterases pertencem ao grupo de serino hidrolases e catalisam a hidrólise de ligações éster-carboxílicas de triacilgliceróis, liberando ácidos graxos e glicerol, com intermediários mono e diacilglicerol (Jaeger et al., 1994; Chen; Daniel; Coolbear, 2003; Hasan; Shah; Hameed, 2006; Nagarajan, 2012).

As lipases hidrolisam, preferencialmente, substratos de cadeia longa, maiores do que 10 carbonos, podendo hidrolisar também substratos de cadeia curta e média. Já as esterases são capazes de hidrolisar somente substratos de cadeia curta e média, menores do que 10 carbonos (Anthonsen et al., 1995; Jaeger; Dijkstra; Reetz, 1999; Nagarajan, 2012). Além da hidrólise, lipases também podem catalisar esterificação, interesterificação e transesterificação (Borrelli \& Trono, 2015). Os substratos preferenciais das lipases, os acilgliceróis de cadeia longa, são insolúveis em água, enquanto as lipases são hidrossolúveis e podem catalisar reações em dois tipos de sistemas, incluindo meios hidrofóbicos e hidrofílicos. Logo, as lipases apresentam a característica única de serem ativas na interface hidrofóbica-hidrofílica, enquanto as esterases atuam somente em condição aquosa, em substratos de cadeia curta, que são solúveis em água (Kuncova et al., 2003; Gupta; Gupta; Rathi, 2004; Soliman et al., 2007).

Com base na especificidade, as lipases podem ser agrupadas em quatro tipos principais: i) enantiosseletiva: pode distinguir enantiômeros em uma mistura racêmica; ii) substrato específico: atua seletivamente sobre um substrato específico em uma mistura de diferentes materiais, facilitando a síntese do produto desejado, iii) regiosseletivo: que são divididos em 1,3 regioespecíficos e 2-regioespecíficos lipases, e iv) não-específico (Borrelli \& Trono, 2015; Verma et al., 2021). As 1,3 lipases regioespecíficas liberam ácidos graxos das posições 1 e 3 do triacilgliceróis e não podem hidrolisar ligações éster em posições secundárias. As lipases 2-regioespecíficas liberam ácidos graxos na posição secundária do triacilgliceróis, produzindo especificamente 1,3-diacilglicerol. As lipases não específicas catalisam a hidrólise de triacilgliceróis em ácidos graxos e glicerol, com intermediários mono e diacilglicerol, e podem hidrolisar o grupo éster em qualquer posição no substrato (Hari Krishna \& Karanth, 2002; Jensen, 1974; Kapoor \& Gupta, 2012). Devido a essas propriedades, as lipases, principalmente de 
origem microbiana, têm ganhado atenção para aplicação na indústria alimentícia, química, farmacêutica, de papel e celulose, biorremediação, cosmética, entre outras (Hasan et al., 2006; Uppada et al., 2017; Javed et al., 2018).

\section{Classificação das lipases bacterianas}

Segundo o sistema de classificação padrão ouro de enzimas lipolíticas bacterianas proposta por Arpigny e Jaeger (1999), as lipases verdadeiras pertencem à família I das oito famílias de enzimas lipolíticas bacterianas, enquanto as famílias II a VIII compreendem as esterases. Jaeger e Eggert (2002) redefiniram a família I, dividindo a subfamília I.5 em duas novas subfamílias (I.5 e I.6), e movendo os membros anteriores da subfamília I.6 para a subfamília I.7, resultando em 7 subfamílias de lipases verdadeiras. Kovacic e colaboradores (2019) expandiram essa classificação original para 19 famílias de enzimas lipolíticas, e oito subfamílias de lipases verdadeiras. No entanto, muitas enzimas lipolíticas permaneceram não classificadas. Por isso, o sistema de classificação de enzimas lipolíticas foi novamente expandido por Hitch e Clavel (2019) para 35 famílias e 11 subfamílias de lipases verdadeiras. A maioria das lipases secretadas pelo gênero Pseudomonas encontradas no leite cru, como P. aeruginosa, P. fluorescens e P. fragi, pertence à subfamília I.1 e I.3 (Arpigny \& Jaeger, 1999; Zhang et al., 2009).

A subfamília I.1 corresponde às lipases com massa molecular de, aproximadamente, $30 \mathrm{kDa}$, com cerca de 285 aminoácidos, incluindo dois resíduos de cisteína, para formar uma ligação dissulfeto. Todas as lipases desta subfamília apresentam o pentapeptídeo consenso GXSXG correspondente ao local da catálise. Para serem secretadas, as lipases deste grupo apresentam uma sequência específica no seu grupamento N-terminal. Além disso, para serem dobradas e secretadas corretamente, as enzimas desta subfamília necessitam da presença de foldases específicas de lipase (Arpigny \& Jaeger, 1999). Enzimas desta subfamília apresentam dois resíduos aspárticos envolvidos no sítio de ligação do $\mathrm{Ca}^{2+}$. A proximidade da ponte dissulfeto e do resíduo aspártico ao sítio catalítico poderia explicar a importância para a estabilidade do sítio ativo destas lipases (Kim et al., 1998). A lipase LipA de Yersinia enterocolitica KM1 também pertence à subfamília I.1, possui massa molecular estimada em 34,2 KDa, sequência consenso GXSXG e compartilha de alta similaridade de sequência com as lipases de Pseudomonas, Burkholderia e Proteus (Ji et al., 2015).

A subfamília I.3 corresponde às lipases com massa molecular de 50 a $65 \mathrm{kDa}$. Este grupo de lipases também apresenta o pentapeptídeo consenso GXSXG e tem características diferentes da subfamília I.1, pois não possui o resíduo de cisteína, não apresenta uma sequência sinal $\mathrm{N}$-terminal e não necessita de quaisquer foldases específicas de lipase para serem dobradas (Arpigny; Jaeger, 1999). Sabe-se que lipases de P. fluorescens (Kumura; Mikawa; Saito, 1993), S. marcescens (Akatsuka et al., 1995) e S. liquefaciens (Figura 1) (Salgado et al., 2021) são desta subfamília. As lipases de subfamília I.3 não têm uma sequência típica de sinal N-terminal e utilizam o sistema de secreção do tipo I chamado transportador ABC (Rosenau \& Jaeger, 2000; Son et al., 2012). 
Figura 1 - Estrutura modelada da lipase de Serratia liquefaciens, isolada do leite cru, com atividade de poliuretanase. O destaque em verde refere-se ao cotovelo nucleofílico da lipase e as esferas em vermelho representam os íons cálcio.

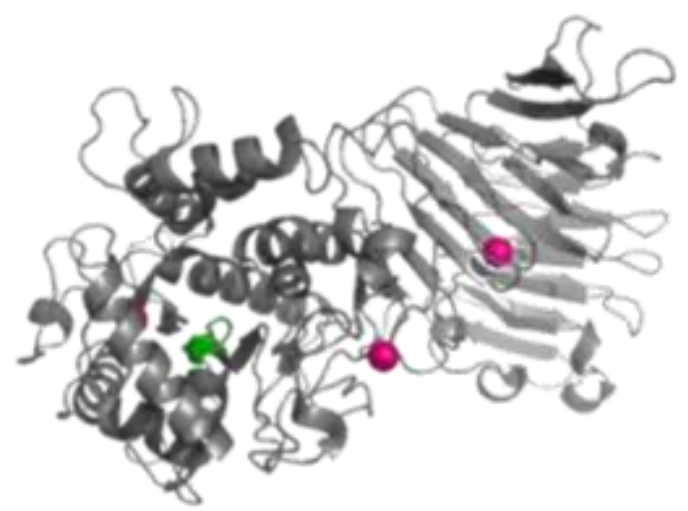

Fonte: Salgado et al., (2021).

\section{Impacto das lipases na indústria laticinista}

A gordura do leite é secretada em uma única estrutura denominada glóbulo de gordura de leite (Figura 2) e consiste de um núcleo composto por, aproximadamente, $98 \%$ de triacilgliceróis coberto com três camadas de fosfolipídios e proteínas (Argov-Argaman et al., 2013). O diâmetro médio dos glóbulos de gordura do leite é de cerca de 4 um, podendo variar de 0,1 a $10 \mu \mathrm{m}$ (Bourlieu et al., 2009). São envolvidos por uma membrana composta por fosfolipídios (fosfatidilcolina, fosfatidiletanolamina, fosfatidilinositol, fosfatidilserina e esfingomielina), gangliosídeos, colesterol, proteínas e glicoproteínas (Lopez; Cauty; Guyomarc'h, 2015; Walter et al., 2020). Processos físicos, tais como formação de espuma, agitação ou homogeneização podem romper as membranas dos glóbulos de gordura do leite. Além disso, a variação de temperatura e o efeito sinérgico de enzimas também podem danificar esta membrana (Muir, 1996). Vale ressaltar que as lipases são capazes de hidrolisar os glóbulos de gordura de leite intactos, enquanto as esterases não o são. Com o rompimento da membrana do glóbulo de gordura, as enzimas lipolíticas têm acesso aos triacilgliceróis (Deeth, 2006).

Figura 2 - Esquema da estrutura do glóbulo de gordura do leite.

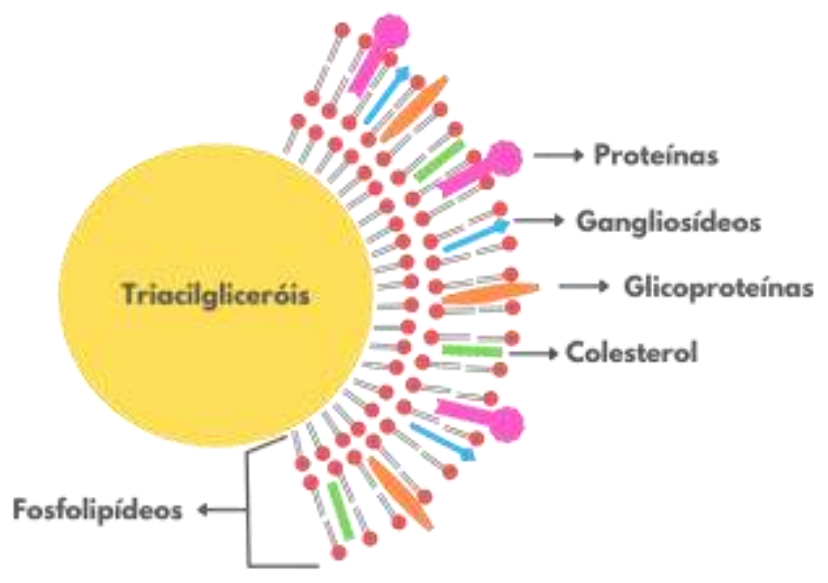

Fonte: Adaptado de Lopez; Cauty; Guyomarc'h, (2015); Walter et al., (2020). 
A gordura do leite é a mais complexa encontrada na natureza e os triacilgliceróis presentes no interior dos glóbulos de gordura possuem mais de 400 ácidos graxos diferentes já identificados (Lopez et al., 2011). Com a utilização de técnicas de cromatografia líquida e espectrometria de massa de alta resolução, Liu et al. (2020) detectaram a presença de 3.454 tipos de triacilgliceróis, embora este ainda não seja o número total de diferentes triacilgliceróis presentes no leite. Foi verificado que, pelo menos 65 diferentes ácidos graxos são constituintes desses triacilgliceróis, dos quais 23 são saturados, 17 são monoinsaturados, 8 são di-insaturados e 17 são poli-insaturados (Liu et al., 2020).

Os produtos da lipólise dos triacilgliceróis são os ácidos graxos e os glicerídeos parciais, di- e monoglicerídeos. Ácidos graxos de cadeia curta, a saber, C2:0, C3:0, C5:0 e C7:0, não foram encontrados nos triacilgliceróis presentes no leite, enquanto os ácidos graxos de maior frequência foram dois ácidos graxos de cadeia curta, C4:0 e C6:0, três ácidos graxos de cadeia média (C8:0, C10:0 e C12:0) e seis ácidos graxos de cadeia longa (C14:0, C16:0, C18:0, C18:1 e C18:2) (Liu et al., 2020). Os ácidos graxos de cadeia curta são muito saborosos mas, em excesso, conferem um sabor desagradável ao leite e produtos lácteos. O sabor é descrito como rançoso, sujo, adstringente, amargo e butírico. Os glicerídeos parciais não alteram o sabor, mas têm propriedades tensoativas que reduzem a capacidade de formação de espuma do leite, um efeito indesejável quando o leite é usado para fazer cappuccino ou café com leite (Deeth, 2020). Ao avaliarem compostos voláteis liberados do leite durante o crescimento de bactérias psicrotróficas, Decimo et al. (2018) identificaram um total de 47 compostos orgânicos e, dentre esses, destacam-se os ácidos graxos butanóico e hexanóico, produtos da lipólise, indicados como potenciais deterioradores do leite.

A presença de lipase bacteriana pode afetar a qualidade do leite fluido e seus produtos (Ribeiro Júnior et al., 2018). No leite pasteurizado, a lipólise é menos provável em razão da temperatura baixa de armazenamento e da vida de prateleira relativamente curta. Geralmente, a lipólise ocorre apenas ao final da vida útil do leite pasteurizado e é caracterizada por sabores como amargo, azedo e, ou pútrido, derivados da alta concentração de ácidos graxos livres presente (Deeth, 2011; Wiking, 2020). A atividade residual de lipase após tratamento térmico do leite pode ser elevada. A lipase produzida por $S$. liquefaciens L135 não teve sua atividade alterada pela pasteurização rápida, e manteve 47\% de atividade após pasteurização lenta, podendo ser associada à deterioração do leite pasteurizado (Salgado et al., 2020).

Em leite UHT é comum a presença de lipases estáveis ao calor, que podem impactar na vida útil e na qualidade do produto. Andrewes (2018) detectaram lipase no leite UHT através da formação de éster metílico e verificaram que quanto maior a quantidade de lipases presente na amostra, maior a deterioração do produto, levando o leite UHT a apresentar um sabor de sabão em torno de duas semanas. No leite em pó, a atividade residual das lipases bacterianas é uma preocupação. Tais enzimas agem lentamente no produto durante o armazenamento, a atividade lipolítica pode ser detectada meses após fabricação e resultar em uma série de prejuízos econômicos quando o leite em pó for utilizado na produção de outros alimentos, como os de confeitaria, por exemplo (Deeth, 2011).

As lipases produzidas por psicrotróficos são consideradas importantes no desenvolvimento de defeitos no sabor e aroma em queijos porque são adsorvidas pelos glóbulos de gordura, ficando retidas na massa do queijo. A presença de lipases em queijos promove a hidrólise da gordura com liberação de ácidos graxos e a formação de ácidos hexanóico, octanóico, decanoico e butírico, que conferem sabor picante, rançoso, gorduroso e de sabão ao produto. O defeito aparece ao longo da maturação como no caso do queijo Minas artesanal produzido na Serra da Canastra em Minas Gerais, sendo ainda mais comum em queijos de maturação prolongada, como Emmental, Gruyère Cheddar, Gouda e Parmesão (Bemfeito et al., 2016; Clark et al., 2009; Forde \& Fitzgerald, 2000; Gan et al., 2016). A presença de bactérias psicrotróficas no creme após a utilização do leite para a produção de queijo Grana Trentino pode ser benéfica, no entanto, devido à atividade lipolítica que tais bactérias apresentam, pode impactar a qualidade da nata e manteiga fabricadas com tal creme (Franciosi et al., 2011). Esses produtos podem apresentar sabores de sabão, amargo e azedo, caracterizado por um alto teor de ácidos graxos (Franciosi et al., 2011; 
Wiking, 2020). Os ácidos graxos presentes são geralmente de cadeia mais longa, porque os ácidos de cadeia mais curta apresentam solubilidade em água e são perdidos no soro de leite (Deeth, 2011).

O ranço hidrolítico é considerado um dos defeitos mais problemáticos da manteiga e está relacionado principalmente com a liberação de ácidos graxos por enzimas lipolíticas, resultando em sabores estranhos descritos como rançosos, amargos e impuros (Deeth, 2020). A concentração alta de ácidos graxos livres na manteiga pode ter origem na ação da lipase nativa no leite cru ou na manteiga, mas as lipases de origem bacteriana também podem ter participação significativa nesta deterioração.

Embora estejam associadas à deterioração de diversos produtos lácteos, as lipases microbianas são usadas na indústria de laticínios para hidrolisar a gordura do leite, melhorar o sabor do iogurte, realçar o sabor do queijo e lipólise da manteiga e do creme de acordo com as necessidades de processamento e acelerar o amadurecimento do queijo.

\section{Potencial de aplicação biotecnológica de lipases bacterianas}

Algumas lipases produzidas por bactérias psicrotróficas têm apresentado potencial de aplicação biotecnológica em diversas indústrias. $Y$. enterocolitica é uma bactéria psicrotrófica que pode ser encontrada no leite cru refrigerado e pasteurizado. O biotipo 1A é capaz de produzir lipase e já foi isolado de produtos lácteos, como sorvete e iogurte (Barton, 2011). A lipase de $Y$. enterocolitica KM1, possui boa termoestabilidade em baixas temperaturas e estabilidade na presença de solventes orgânicos de baixa concentração, o que a faz ser uma boa candidata para aplicação nas reações de esterificação ou transesterificação na indústria de detergentes (Ji et al., 2015).

Pseudomonas fluorescens, bactéria psicrotrófica geralmente encontrada no leite cru refrigerado, também apresenta atividade lipolítica (Narvhus et al., 2021). Tal bactéria tem sido considerada um biocatalisador eficiente para diversos processos biotecnológicos, como agregação de valor em produtos por meio de reações de esterificação e hidrólise, bem como por possuir alto rendimento e ser enantiosseletiva (Rios et al., 2018).

Outra bactéria psicrotrófica capaz de produzir lipase e comumente encontrada em leite cru refrigerado é $S$. liquefaciens. Tal lipase, estável ao calor, foi identificada como poliuretanase, sendo que as análises in silico desta lipase mostraram alta especificidade para uretano, o que sugere potencial de biodegradação de poliuretanos, que são polímeros plásticos (Salgado et al., 2021). À medida que os resíduos de poliuretano se acumulam, métodos estão sendo buscados para degradar e reciclar este polímero recalcitrante e artificial. Assim, microrganismos e enzimas capazes de degradarem os poliuretanos apresentam características de considerável interesse biotecnológico pois são alternativas para a reciclagem deste composto xenobiótico (Howard; Norton; Burks, 2012; Shah et al., 2013).

\section{Considerações Finais}

As lipases derivadas de bactérias psicrotróficas são enzimas que causam uma preocupação na indústria laticinista, e podem causar alterações de sabor e aroma no leite cru refrigerado e em seus derivados, tornando-os inaceitáveis para os consumidores e ocasionando prejuízo à indústria. Por outro lado, as lipases vêm sendo consideradas biocatalisadores versáteis, com amplo potencial de aplicação biotecnológica, o que é interessante para a indústria. Portanto, são necessários mais estudos acerca de tais enzimas, dada a necessidade de controle de sua atividade em meio industrial, como também pelo seu relevante potencial biotecnológico.

Trabalhos futuros devem contemplar os avanços a respeito do potencial de aplicação biotecnológico das lipases, nas mais diversas áreas industriais, principalmente, na indústria de alimentos. Também é de extrema relevância que estudos posteriores contemplem soluções a respeito dos defeitos que a atividade lipolítica pode causar em produtos alimentícios, em especial nos produtos lácteos, que representam uma parcela importante do mercado alimentício. 


\section{Agradecimentos}

Este trabalho teve o apoio do Conselho Nacional de Desenvolvimento Científico e Tecnológico (CNPq).

\section{Referências}

Akatsuka, H., Kawai, E., Omori, K., \& Shibatani, T. (1995). The three genes lipB, lipC, and lipD involved in the extracellular secretion of the Serratia marcescens lipase which lacks an N-terminal signal peptide. Journal of Bacteriology, 177(22), 6381-6389.

Andrewes, P. (2018). Indirect detection of lipase in UHT milk by measuring methyl ester formation. International Dairy Journal, $79,1-4$.

Anthonsen, H. W., Baptista, A., Drabløs, F., Martel, P., Petersen, S. B., Sebastião, M., \& Vaz, L. (1995). Lipases and esterases: a review of their sequences, structure and evolution. Biotechnology Annual Review. Elsevier, 1, 315-371.

Argov-Argaman, N., Mida, K., Cohen, B. C., Visker, M., \& Hettinga, K. (2013). Milk fat content and DGAT1 genotype determine lipid composition of the milk fat globule membrane. PLoS One, 8(7), 1-8.

Arpigny, J. L., \& Jaeger, K. E. (1999). Bacterial lipolytic enzymes: classification and properties. Biochemical Journal, 343(1), 177-183.

Barton, M. D. Pathogens in Milk | Yersinia enterocolitica. (2011). Encyclopedia of Dairy Sciences (Second Edition), $117-123$.

Bemfeito, R. M., Rodrigues, J. F., Silva, J. G., Abreu, L. R. (2016). Temporal dominance of sensations sensory profile and drivers of liking of artisanal Minas cheese produced in the region of Serra da Canastra, Brazil. Journal of Dairy Science, 99(10), 7886-7897.

Borrelli, G. M., \& Trono, D. (2015). Recombinant lipases and phospholipases and their use as biocatalysts for industrial applications. International Journal of Molecular Sciences, 16(9), 20774-20840.

Brasil. Ministério da Agricultura, Pecuária e Abastecimento (MAPA) (2018). Instrução Normativa 76 de novembro de 2018. Aprova os Regulamentos Técnicos que fixam a identidade e as características de qualidade que devem apresentar o leite cru refrigerado, o leite pasteurizado e o leite pasteurizado tipo A. http://www.in.gov.br/materia/-/asset_publisher/Kujrw0TZC2Mb/content/id/52750137/do1-2018-11-30-instrucao-normativa-n-76-de-26-de-novembro-de2018-52749894IN\%2076

Brito, M. A., Brito, J. R., Arcuri, E., Lange, C., Silva, M., Souza, G. (2016). Agência de Informação Embrapa. Agronegócio do Leite. Composição. https://www.agencia.cnptia.embrapa.br/Agencia8/AG01/arvore/AG01_128_21720039243.html

Chen, L. D. R. M., Daniel, R. M., \& Coolbear, T. (2003). Detection and impact of protease and lipase activities in milk and milk powders. International Dairy Journal, 13(4), 255-275.

Clark, S., Costello, M., Drake, M., \& Bodyfelt, F. (Eds). (2009). The sensory evaluation of dairy products. Springer Science \& Business Media.

Decimo, M., Morandi, S., Silvetti, T., \& Brasca, M. (2014). Characterization of gram-negative psychrotrophic bacteria isolated from Italian bulk tank milk. Journal of Food Science, 79(10), M2081-M2090.

Decimo, M., Cabeza, M. C., Ordóñez, J. A., De Noni, I., \& Brasca, M. (2018). Volatile organic compounds associated with milk spoilage by psychrotrophic bacteria. International Journal of Dairy Technology, 71(3), 593-600.

Deeth, H. C. (2006). Lipoprotein lipase and lipolysis in milk. International Dairy Journal, 16(6), 555-562.

Deeth, H. C. (2011). Lipolysis and Hydrolytic Rancidity. In: Encyclopedia of Dairy Sciences, $2^{\text {nd }}$ Ed, Oxford: Academic Press.721-726.

Deeth H.C. (2020) Stability and Spoilage of Lipids in Milk and Dairy Products. In: McSweeney P.L.H., Fox P.F., O'Mahony J.A. (eds) Advanced Dairy Chemistry, v. 2. Springer. 345-373.

Forde, A., Fitzgerald, G. F. (2000). Biotechnological approaches to the understanding and improvement of mature cheese flavour. Current Opinion in Biotechnology, 11(5), 484-489.

Franciosi, E., De Sabbata, G., Gardini, F., Cavazza, A., Poznanski, E. (2011). Changes in psychrotrophic microbial populations during milk creaming to produce Grana Trentino cheese. Food Microbiology, 28(1), 43-51.

Gan, H. H., Yan, B., Linforth, R. S. T., Fisk, I. D. (2016). Development and validation of an APCI-MS/GC-MS approach for the classification and prediction of Cheddar cheese maturity. Food Chemistry, 190, 442-447.

Gupta, R., Gupta, N., \& Rathi, P. (2004). Bacterial lipases: an overview of production, purification and biochemical properties. Applied Microbiology and Biotechnology, 64(6), 763-781.

Hantsis-Zacharov, E., \& Halpern, M. (2007). Culturable psychrotrophic bacterial communities in raw milk and their proteolytic and lipolytic traits. Applied and Environmental Microbiology, 73(22), 7162-7168.

Hari Krishna, S., \& Karanth, N. G. (2002). Lipases and lipase-catalyzed esterification reactions in nonaqueous media. Catalysis Reviews - Science and Engineering, 44(4), 499-591.

Hasan, F., Shah, A. A., \& Hameed, A. (2006). Industrial applications of microbial lipases. Enzyme and Microbial Technology, 39(2), 235-251.

Hitch, T. C. A., Clavel, T. (2019). A proposed update for the classification and description of bacterial lipolytic enzymes. PeerJ, 7 e7249. 
Howard, G. T., Norton, W. N., \& Burks, T. (2012). Growth of Acinetobacter gerneri P7 on polyurethane and the purification and characterization of a polyurethanase enzyme. Biodegradation, 23(4), 561-573.

Jaeger, K. E., Dijkstra, B. W., \& Reetz, M. T. (1999). Bacterial biocatalysts: molecular biology, three-dimensional structures, and biotechnological applications of lipases. Annual Reviews in Microbiology, 53(1), 315-351.

Jaeger, K. E., \& Eggert, T. (2002). Lipases for biotechnology. Current opinion in biotechnology, 13(4), 390-397.

Jaeger, K. E., Ransac, S., Dijkstra, B. W., Colson, C., Van Heuvel, M., \& Misset, O. (1994). Bacterial lipases. FEMS Microbiology Reviews, $15(1)$, 29-63.

Javed, S., Azeem, F., Hussain, S., Rasul, I., Siddique, M. H., Riaz, M., \& Nadeem, H. (2018). Bacterial lipases: a review on purification and characterization. Progress in Biophysics and Molecular Biology, 132, 23-34.

Jensen, R. G. (1974). Characteristics of the lipase from the mold, Geotrichum candidum: A review. Lipids, 9(3), $149-157$.

Ji, X., Li, S., Wang, B., Zhang, Q., Lin, L., Dong, Z., Wei, Y. (2015). Expression, purification, and characterization of a functional, recombinant, cold-active lipase (LipA) from psychrotrophic Yersinia enterocolitica. Protein Expression and Purification, 115, 125-131.

Kapoor, M., \& Gupta, M. N. (2012). Lipase promiscuity and its biochemical applications. Process Biochemistry, 47(4), 555-569.

Kim, H. K., Park, S. Y., Lee, J. K., \& Oh, T. K. (1998). Gene cloning and characterization of thermostable lipase from Bacillus stearothermophilus L1. Bioscience, Biotechnology, and Biochemistry, 62(1), 66-71.

Kovacic, F., Babic, N., Krauss, U., Jaeger, K. (2019). Classification of lipolytic enzymes from bacteria. Aerobic Utilization of Hydrocarbons, Oils and Lipids, 24, 255-289.

Kumura, H., Mikawa, K., \& Saito, Z. (1993). Influence of milk proteins on the thermostability of the lipase from Pseudomonas fluorescens 33. Journal of Dairy Science, 76(8), 2164-2167.

Kuncova, G., Szilva, J., Hetflejs, J., \& Sabata, S. (2003). Catalysis in organic solvents with lipase immobilized by sol-gel technique. Journal of Sol-Gel Science and Technology, 26(1-3), 1183-1187.

Liu, Z., Li, C., Pryce, J., Rochfort, S. (2020). Comprehensive characterization of bovine milk lipids: triglycerides. ACS Omega, 5(21), $12573-12582$.

Lopez, C., Briard-Bion, V., Ménard, O., Beaucher, E., Rousseau, F., Fauquant, J., \& Robert, B. (2011). Fat globules selected from whole milk according to their size: different compositions and structure of the biomembrane, revealing sphingomyelin-rich domains. Food Chemistry, 125(2), 355-368.

Lopez, C., Cauty, C., \& Guyomarc'h, F. (2015). Organization of lipids in milks, infant milk formulas and various dairy products: role of technological processes and potential impacts. Dairy Science \& Technology, 95(6), 863-893.

Muir, D. D. (1996). The shelf-life of dairy products: 1. Factors influencing raw milk and fresh products. International Journal of Dairy Technology, 49(1), 2432.

Nagarajan, S. (2012). New tools for exploring “old friends-microbial lipases”. Applied Biochemistry and Biotechnology, 168(5), 1163-1196.

Narvhus, J. A., Bækkelund, O. D., Tidemann, E. M., Østlie, H. M., Abrahamsen, R. K. (2021). Isolates of Pseudomonas spp. From cold-stored raw milk show variation in proteolytic and lipolytic porperties. International Dairy Journal, 123(December, 2021), 105049.

Pereira, A. S., Shitsuka, D. M., Parreira, F. J. \& Shitsuka, R (2018). Methodology of cientific research. [e-Book]. Santa Maria: UAB / NTE / UFSM. https://repositorio.ufsm.br/bitstream/handle/1/15824/Lic_Computacao_Metodologia-Pesquisa-Cientifica.pdf?sequence=1 .

Ribeiro Júnior, J. C., De Oliveira, A. M., Silva, F. G., Tamanini, R., De Oliveira, A. L. M., Beloti, V. (2018) The main spoilage-related psychrotrophic bacteria in refrigerated raw milk. Journal of Dairy Science, 101(1), 75-83.

Rios, N. S., Pinheiro, B. B., Pinheiro, M. P., Bezerra, R. M., Santos, J. C. S., Gonçalves, L. R. B. (2018). Biotechnological potential of lipases from Pseudomonas: Sources, properties and applications. Process Biochemistry, 75, 99-120.

Rosenau, F., \& Jaeger, K. E. (2000). Bacterial lipases from Pseudomonas: regulation of gene expression and mechanisms of secretion. Biochimie, 82(11), $1023-1032$.

Salgado, C. A., Almeida, F. A., Barros, E., Baracat-Pereira, M. C., Baglinière, F., Vanetti, M. C. D. (2021). Identification and characterization of a polyurethanase with lipase activity from Serratia liquefaciens isolated from cold raw cow's milk. Food Chemistry, $337,127954$.

Salgado, C. A., Baglinière, F., Vanetti, M. C. D. (2020). Spoilage potential of a het-stable lipase produced by Serratia liquefaciens isolated from cold raw milk. LWT, 126(May, 2020), 109289.

Sangeetha, R., Arulpandi, I., \& Geetha, A. (2011). Bacterial lipases as potential industrial biocatalysts: An overview. Research Journal of Microbiology, 6(1), $1-24$

Shah, Z., Krumholz, L., Aktas, D. F., Hasan, F., Khattak, M., \& Shah, A. A. (2013). Degradation of polyester polyurethane by a newly isolated soil bacterium, Bacillus subtilis strain MZA-75. Biodegradation, 24(6), 865-877.

Soliman, N. A., Knoll, M., Abdel-Fattah, Y. R., Schmid, R. D., \& Lange, S. (2007). Molecular cloning and characterization of thermostable esterase and lipase from Geobacillus thermoleovorans YN isolated from desert soil in Egypt. Process Biochemistry, 42(7), 1090-1100. 
Research, Society and Development, v. 10, n. 13, e230101321213, 2021

(CC BY 4.0) | ISSN 2525-3409 | DOI: http://dx.doi.org/10.33448/rsd-v10i13.21213

Son, M., Moon, Y., Oh, M. J., Han, S. B., Park, K. H., Kim, J. G., \& Ahn, J. H. (2012). Lipase and protease double deletion mutant of Pseudomonas fluorescens suitable for extracellular protein production. Applied and Environmental Microbiology, 78(23), 8454-8462.

Sørhaug, T., \& Stepaniak, L. (1997). Psychrotrophs and their enzymes in milk and dairy products: quality aspects. Trends in Food Science \& Technology, 8(2), $35-41$.

Uppada, S. R., Akula, M., Bhattacharya, A., \& Dutta, J. R. (2017). Immobilized lipase from Lactobacillus plantarum in meat degradation and synthesis of flavor esters. Journal of Genetic Engineering and Biotechnology, 15(2), 331-334.

Verma, S., Meghwanshi, G. K., \& Kumar, R. (2021). Current perspectives for microbial lipases from extremophiles and metagenomics. Biochimie, 182(March), 23-36.

Vithanage, N. R., Dissanayake, M., Bolge, G., Palombo, E. A., Yeager, T. R., \& Datta, N. (2016). Biodiversity of culturable psychrotrophic microbiota in raw milk attributable to refrigeration conditions, seasonality and their spoilage potential. International Dairy Journal, 57, 80-90.

Walter, L., Shrestha, P., Fry, R., Leury, B. J., Logan, A. (2020). Lipid metabolic differences in cows producing small or large milk fat globules: Fatty acid origin and degree of saturation. Journal of Dairy Science, 103(2), 1920-1930.

Wiking, L. (2020). Milking and handling of raw milk | Influence on free fatty acids. Reference Module in Food Science. 2020.

Yuan, L., Sadiq, F. A., Liu, T., Flint, S., Chen, J., Yang, H., Gu, J., Zhang, G., He, G. (2017). Psychrotrophic bacterial populations in Chinese raw dairy milk. $L W T, 84,409-418$.

Zhang, A., Gao, R., Diao, N., Xie, G., Gao, G., \& Cao, S. (2009). Cloning, expression and characterization of an organic solvent tolerant lipase from Pseudomonas fluorescens JCM5963. Journal of Molecular Catalysis B: Enzymatic, 56(2-3), 78-84.

Zhang, D., Palmer, J., Teh, K. H., Biggs, P., Flint, S. (2019). 16S rDNA high-throughput sequencing and MALDI-TOF MS are complementary When studying psychrotrophic bacterial diversity of raw cow's milk. International Dairy Journal, 97, 86-91. 